\title{
Brassinin induces G1 phase arrest through increase of p21 and p27 by inhibition of the phosphatidylinositol 3-kinase signaling pathway in human colon cancer cells
}

\author{
YASUYUKI IZUTANI, SHINGO YOGOSAWA, YOSHIHIRO SOWA and TOSHIYUKI SAKAI \\ Department of Molecular-Targeting Cancer Prevention, Graduate School of Medical Science, \\ Kyoto Prefectural University of Medicine, Kawaramachi-Hirokoji, Kamigyo-ku, Kyoto 602-8566, Japan
}

Received August 30, 2011; Accepted October 7, 2011

DOI: $10.3892 /$ ijo.2011.1246

\begin{abstract}
The phosphatidylinositol 3-kinase (PI3K) signaling pathway is activated in a broad spectrum of human cancers, including colon cancer. The natural product brassinin is a type of indole compound derived from cruciferous vegetables, and has been shown to have anti-proliferative effects against cancer for both in vivo and in vitro models. Here, we show for the first time that brassinin inhibits cell growth in human colon cancer cells by arresting the cell cycle at the G1 phase via inhibition of the PI3K signaling pathway. Brassinin increased the expression of p21 and p27, resulting in hypophosphorylation of the retinoblastoma gene (RB). Knockdown of p21 or p27 by each siRNA significantly repressed G1 phase arrest induced by brassinin. The increase of p21 and p27 was associated with inhibition of the PI3K signaling pathway. In addition, exogenous expression of constitutively active Akt represses the cell cycle arrest at G1 phase induced by brassinin. These results suggest the possibility that brassinin inhibits the PI3K signaling pathway and upregulates the expression of p21 and p27, thereby inducing G1 phase arrest.
\end{abstract}

\section{Introduction}

The cancer preventive effect of vegetables of the family Cruciferae, such as broccoli, brussel sprouts and cabbages, is attributed to their various phytochemical constituents $(1,2)$. Brassinin is one of the components of the cruciferous vegetables,

Correspondence to: Dr Toshiyuki Sakai, Department of MolecularTargeting Cancer Prevention, Graduate School of Medical Science, Kyoto Prefectural University of Medicine, Kawaramachi-Hirokoji, Kamigyo-ku, Kyoto 602-8566, Japan

E-mail: tsakai@koto.kpu-m.ac.jp

Abbreviations: brassinin, methyl (1H-indol-3-ylmethyl)dithiocarbamate; RB, retinoblastoma gene; cdk, cyclin-dependent kinase; PI3K, phosphatidylinositol 3-kinase; PDK, PI3K-dependent kinase

Key words: cell cycle, phosphatidylinositol 3-kinase, Akt, p21, p27, brassinin and is expected to be useful for anti-cancer activities. For example, brassinin has been shown to inhibit carcinogenesis in murine skin model inducing phase 2 enzymes $(3,4)$. Recently, brassinin has been reported as a new class of compounds with in vivo anti-cancer activity that is mediated through the inhibition of indoleamine 2,3-dioxygenase (IDO), a pro-tolerogenic enzyme that drives immune escape in cancer (5). Brassinin has also been reported as a potent inhibitor of the growth of cancer cells (6). However, the comprehensive molecular mechanism by which brassinin inhibits cell growth is still unknown.

Phosphatidylinositol 3 kinase (PI3K) activates Akt via PI3K-dependent kinase (PDK) and is responsible for various intracellular events such as regulation of cell survival, proliferation, or migration (7-9). Deregulation of PI3K-Akt signaling pathway has also been implicated in cancer development $(7,8)$. LY294002, a specific inhibitor of PI3K, has been reported to increase expressions of p21 and p27, well-known cyclindependent kinase (cdk) inhibitors that belong to the CIP/KIP family $(10,11)$, inducing $\mathrm{G} 1$ phase arrest in various cancer cell lines $(9,12,13)$.

We found for the first time that brassinin inhibits cell growth in human colon cancer HT-29 cells by arresting the cell cycle at the G1 phase. We additionally found that brassinin increased expressions of p21 and p27 via inhibition of the PI3K-Akt signaling pathway.

\section{Materials and methods}

Cell culture and reagents. Human colon cancer HT-29 cells were maintained in DMEM containing $10 \%$ fetal bovine serum, $2 \mathrm{mmol} / \mathrm{l}$ glutamine, and antibiotics $(50 \mathrm{U} / \mathrm{ml}$ penicillin and $100 \mathrm{mg} / \mathrm{ml}$ streptomycin) at $37^{\circ} \mathrm{C}$ in a humidified atmosphere with $5 \% \mathrm{CO}_{2}$. Methyl (1H-indol-3-ylmethyl)dithiocarbamate (brassinin) was purchased from LKT Laboratories Inc. (St. Paul, MN) and was dissolved in DMSO. Actinomycin D was purchased from Sigma (St. Louis, MO). LY294002 was purchased from Cell Signaling Technology (Beverly, MA). Akt inhibitor IV was purchased from Calbiochem (San Diego, CA).

Cell viability assay. HT-29 cells were incubated with or without brassinin as indicated for 24-72 h. Cell viability was measured 
by WST-8 assay using Cell Counting Kit-8 (Dojindo, Japan) according to the manufacturer's instructions.

Flow cytometric analysis. Cells were incubated with or without brassinin as indicated and harvested. The cells were then fixed in $70 \%$ cold ethanol and stained with $100 \mu \mathrm{g} / \mathrm{ml}$ propidium iodide. The stained cells were analyzed using FACSCalibur (BectonDickinson, Franklin Lakes, NJ). The data were analyzed using Modfit LT software (Verity Software, Topsham, ME).

Protein isolation and Western blot analysis. Cells were incubated with or without brassinin as indicated and lysed in lysis buffer (50 mM Tris-HCl, 1\% SDS, $2 \mu \mathrm{g} / \mathrm{ml}$ leupeptin, $2 \mu \mathrm{g} / \mathrm{ml}$ aprotinin, $0.1 \%$ 2-mercaptoethanol, and $1 \mathrm{mM}$ phenylmethylsulfonyl fluoride). The lysates were sonicated and centrifuged at $14,000 \mathrm{x} g$ for $20 \mathrm{~min}$ at $4^{\circ} \mathrm{C}$, and the supernatants were collected. Equal amounts of the lysate were analyzed by SDS-PAGE and transferred to PVDF membrane (Millipore, Bedford, MA). The following antibodies were used as the primary antibody: rabbit anti-human p21 polyclonal antibody (C-19, Santa Cruz Biotechnology), rabbit anti-human p27 polyclonal antibody (C-19, Santa Cruz Biotechnology), rabbit anti-human Akt, phospho-Akt (Ser473), p42/44 MAPK, phospho-p42/44 MAPK, PTEN, phospho-PTEN, GSK3 $\beta$, phospho-GSK3 $\beta$ (Ser9), PDK1, phospho-PDK1 antibodies (Cell Signaling Technology, Inc.), and mouse anti-human pRB monoclonal antibody (G3-245, Pharmingen). The signals were detected with the ECL Western blot analysis system (GE Healthcare, Piscataway, NJ).

$R N A$ isolation and real-time quantitative RT-PCR. Total RNA was isolated from HT-29 cells treated with or without brassinin as indicated using Sepasol-RNA I Super (Nacalai Tesque Inc., Kyoto, Japan) according to the manufacturer's instructions. Total RNA was reverse-transcribed to cDNA using oligo(dT) primers and M-MLV reverse transcriptase (Promega, San Luis Obispo, CA). Total reaction mixture $(25 \mu \mathrm{l})$ was incubated at $37^{\circ} \mathrm{C}$ for $1 \mathrm{~h}$. An equivalent volume $(1 \mu \mathrm{l})$ of cDNA solution was used for the quantification of specific cDNA by real-time quantitative RT-PCR. Quantitative real-time RT-PCR was carried out using an ABI 7300 real-time PCR system (Applied Biosystems, Foster, CA). For mRNA stability assay, $3 \mu \mathrm{g} / \mathrm{ml}$ actinomycin D was added directly to the medium. The expression levels of p21 and p27 were normalized to the level of GAPDH mRNA of the same sample.

siRNA transfection. $\mathrm{p} 21$ siRNA(s415), p27 siRNA(s2838), and negative control siRNA were purchased from Ambion. Cells were transfected with $10 \mathrm{nmol} / \mathrm{l}$ siRNA using Lipofectamine ${ }^{\mathrm{TM}}$ RNAiMAX (Invitrogen).

Transfection of Akt expression plasmids. Cells were plated at $1 \times 10^{5}$ cells in 6 -well plates, and $6 \mu \mathrm{g}$ per well of Akt expression plasmid vector (wild-type Akt, mutant Akt, or constitutively active Akt) or empty vector as a negative control was transiently transfected with HilyMax (Dojindo). These Akt expression plasmid vectors were kindly provided by Dr John D. Minna (Hamon Center for Therapeutic Oncology Research, University of Texas Southwestern Medical Center) and Dr Jim Woodgett (The Samuel Lunenfeld Research Institute, Mount Sinai Hospital).
Statistical analysis. Statistical evaluation of the data was performed using the Student's t-test, and $\mathrm{p}<0.01$ was considered significant.

\section{Results}

Brassinin induces $G 1$ phase arrest in HT-29 cells. We investigated the effect of various concentrations of brassinin on the growth of HT-29 cells (Fig. 1A). Dose-dependent and time-dependent inhibition of cell growth was observed at concentrations of $200 \mu \mathrm{mol} / \mathrm{l}$ or more. To elucidate the effect of brassinin on the cell cycle progression, the DNA content of nuclei of HT-29 cells was measured by flow cytometric analysis (Fig. 1B and C). Twenty-four hours after the treatment, the cells at the G1 phase increased from $36.2 \pm 0.2 \%$ by DMSO treatment alone to $50.1 \pm 1.5,72.9 \pm 0.1$, and $55.1 \pm 2.7 \%$ by treatment with 200,300 , and $400 \mu \mathrm{mo} / \mathrm{l}$ brassinin, respectively. The results clearly show that brassinin inhibits the growth of human colon cancer HT-29 cells by arresting them at the G1 phase.

Brassinin up-regulates expressions of p21 and p27 proteins in HT-29 cells. To elucidate the mechanism of G1 arrest by the treatment with brassinin, we examined the expressions of proteins regulating the $\mathrm{G} 1 / \mathrm{S}$ transition by Western blotting. As shown in Fig. 2A and B, we found that brassinin increased p21 and p27 protein expressions in a dose- and time-dependent manner. There were no obvious changes in expressions of INK4 family members such as $\mathrm{p} 15^{\mathrm{INK} 4 \mathrm{~b}}, \mathrm{p} 16^{\text {INK4a }}, \mathrm{p} 18^{\mathrm{INK} 4 \mathrm{c}}$, and $\mathrm{p} 19^{\mathrm{INK} 4 \mathrm{~d}}$ (data not shown). In addition, we examined the phosphorylation status of the RB protein in HT-29 cells treated with brassinin. A hyperphosphorylated form of the RB protein (ppRB) was converted into a hypophosphorylated form (pRB) 6-24 h after the treatment (Fig. 2B), consistent with the induction of p21 and p27 protein expressions. These results suggest that brassinin up-regulates p21 and p27 proteins and inhibits phosphorylation of $\mathrm{RB}$ protein.

Brassinin up-regulates expression of p21 but not p27 mRNA in HT-29 cells. Next, we examined the mRNA expressions of p21 and p27 in the cells treated with brassinin using real-time quantitative RT-PCR. As shown in Fig. 2C, p21 mRNA was dose-dependently increased by the treatment with brassinin, but p27 mRNA was not induced. We next investigated whether brassinin could activate the promoter of the p21 gene, but brassinin did not affect its promoter activity (data not shown). To investigate whether a post-transcriptional regulation mechanism was involved in the increase of p21 mRNA by brassinin, we next performed a series of mRNA stability studies. Since the time course study indicated that p21 mRNA was sufficiently increased $6 \mathrm{~h}$ after the treatment with brassinin (Fig. 3A), actinomycin $\mathrm{D}$, an inhibitor of de novo mRNA synthesis, was added to the cells $6 \mathrm{~h}$ after the treatment with or without brassinin to prevent p21 mRNA synthesis. As shown in Fig. 3B, the half-life of p21 mRNA in the cells treated with brassinin was apparently increased compared with that in control cells (Fig. 3B). These results suggest that brassinin increases the amount of p21 mRNA via stabilization of p21 mRNA, at least partially.

Both p21 and p27 are potential targets for brassinin in HT-29 cells. To determine if p21 and p27 are involved in cell cycle 
A
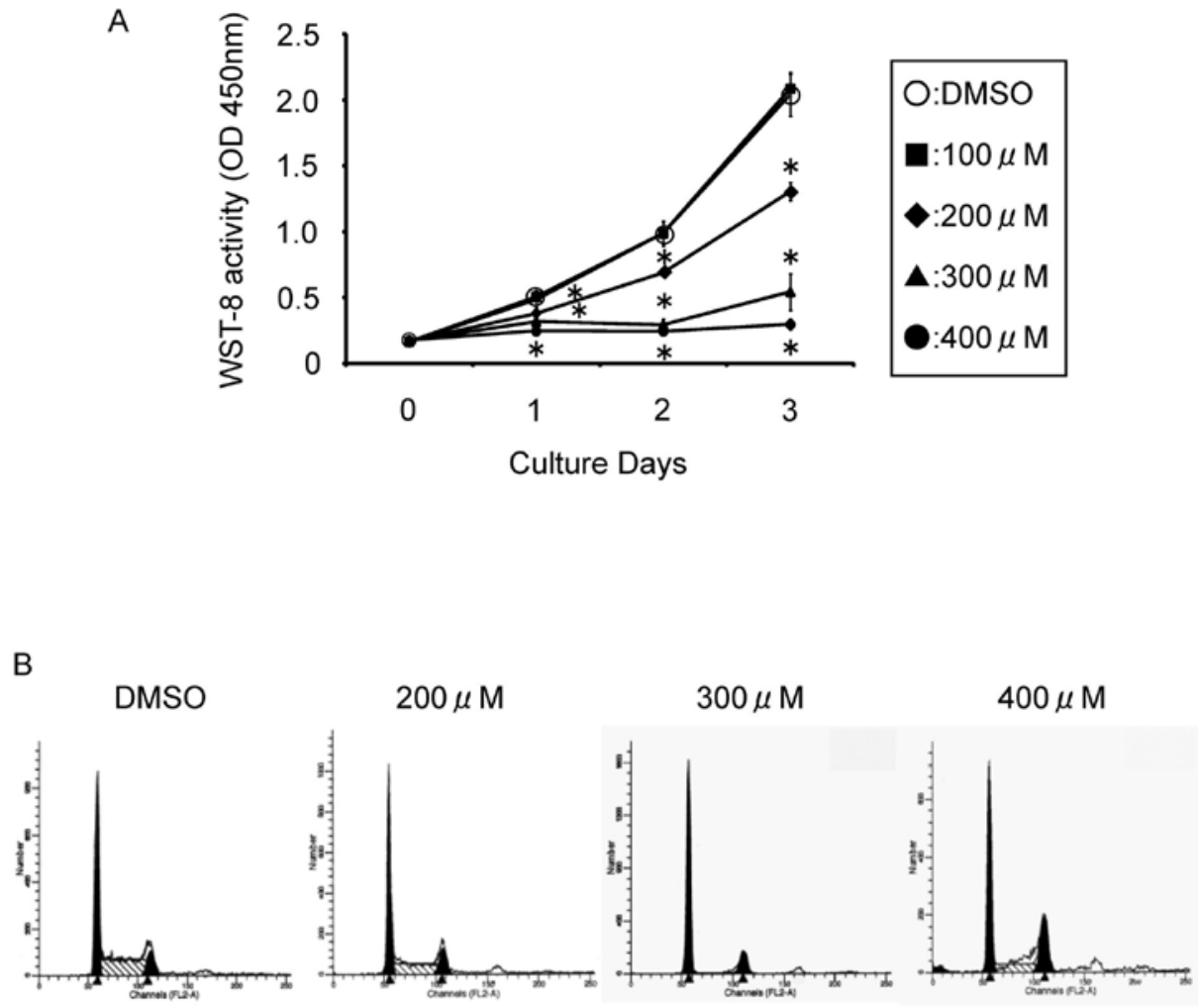

C

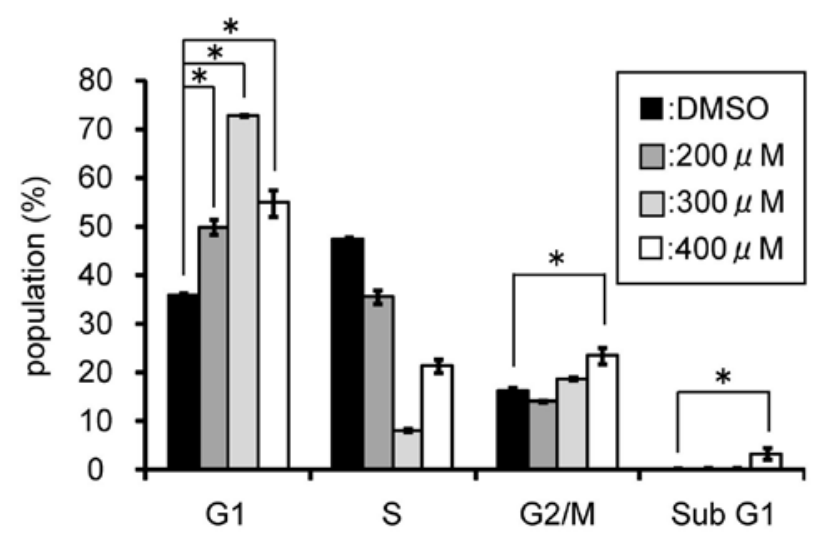

Figure 1. Brassinin inhibits growth of HT-29 cells via induction of cell cycle arrest at G1 phase. (A) Growth inhibitory effect of brassinin on HT-29 cells. Cells were treated with brassinin at the indicated concentrations for $24 \mathrm{~h}$, and the cell viability was evaluated with WST- 8 assay. The data represent means of triplicate experiments and are shown as means \pm SD. "p $<0.01$, compared with the DMSO-treated control. (B and C) Flow cytometric analysis of HT-29 cells treated with brassinin. Cells were treated with brassinin at the indicated concentrations for $24 \mathrm{~h}$. The DNA contents of the cells were analyzed by flow cytometry as described in Materials and methods. The representative histograms are shown in (B), and analytical data of the percentage in each phase of the cell cycle are shown in (C). The data represent means of triplicate experiments and are shown as means $\pm \mathrm{SD}$. ${ }^{\mathrm{p}}<0.01$, compared with the DMSO-treated control.

arrest induced by brassinin, we examined the effects of knockdown of p21 and/or p27 by each siRNA on the induction of cell cycle arrest by brassinin. As expected, treatment with p21 and/or p27 siRNA resulted in a decrease of the protein levels of p21 and/or p27 (Fig. 4A). As shown in Fig. 4B and C, the populations at $\mathrm{G} 1$ phase among the cells treated with 300 and $400 \mu \mathrm{mol} / 1$ brassinin were significantly decreased in the cells treated with p27 siRNA compared with those of the cells treated with control siRNA. In contrast, p21 siRNA slightly but significantly decreased the G1 population. These results suggest that increase of p27 and/or p21 at least partially contributes to the G1 phase arrest induced by brassinin in HT-29 cells.

Brassinin inhibits the PI3K-Akt pathway in HT-29 cells. The PI3K-Akt signaling pathway is considered as one of the most 
A

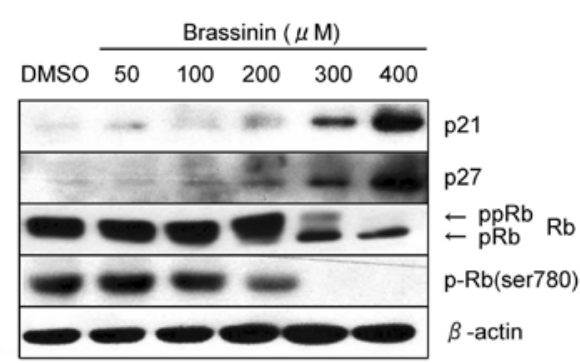

B

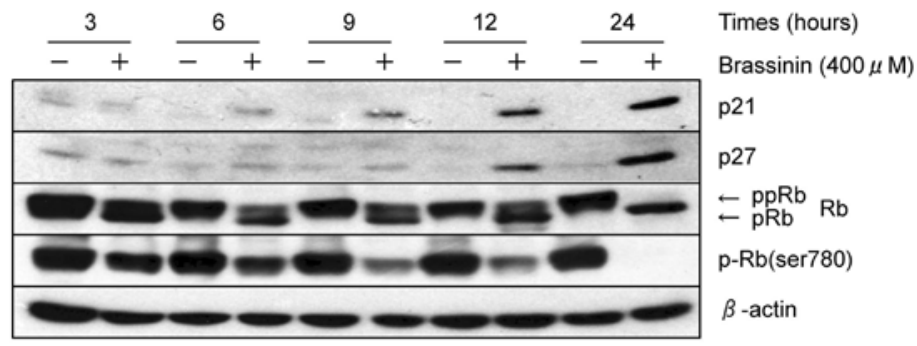

C
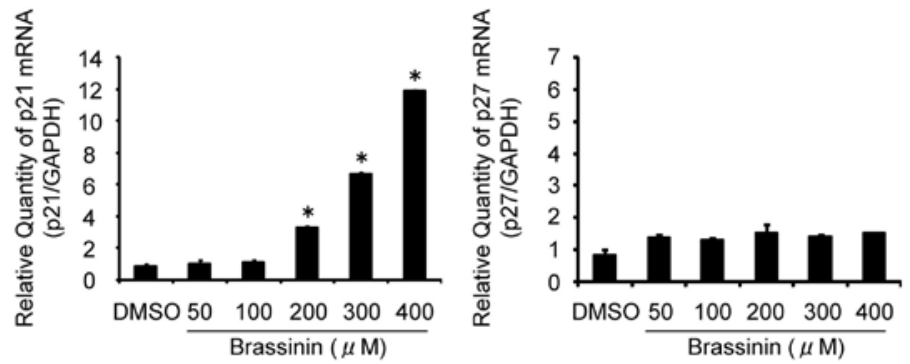

Figure 2. Brassinin induces p21 and p27 protein expressions in HT-29 cells. HT-29 cells were treated with brassinin at the indicated concentrations for $24 \mathrm{~h}$ (A) or treated with DMSO alone (-) or $400 \mu \mathrm{mol} / \mathrm{l}$ brassinin (+) for the indicated periods (B). (C) The expression levels of p21 (left) and p27 (right) mRNA measured using a real-time RT-PCR system. HT-29 cells were treated with brassinin at the indicated concentrations for $24 \mathrm{~h}$. The expression levels of p21 and p27 mRNA were normalized by the level of GAPDH mRNA of the same sample. The data represent means of triplicate experiments and are shown as means \pm SD. "p $<0.01$, compared with the DMSO-treated control.
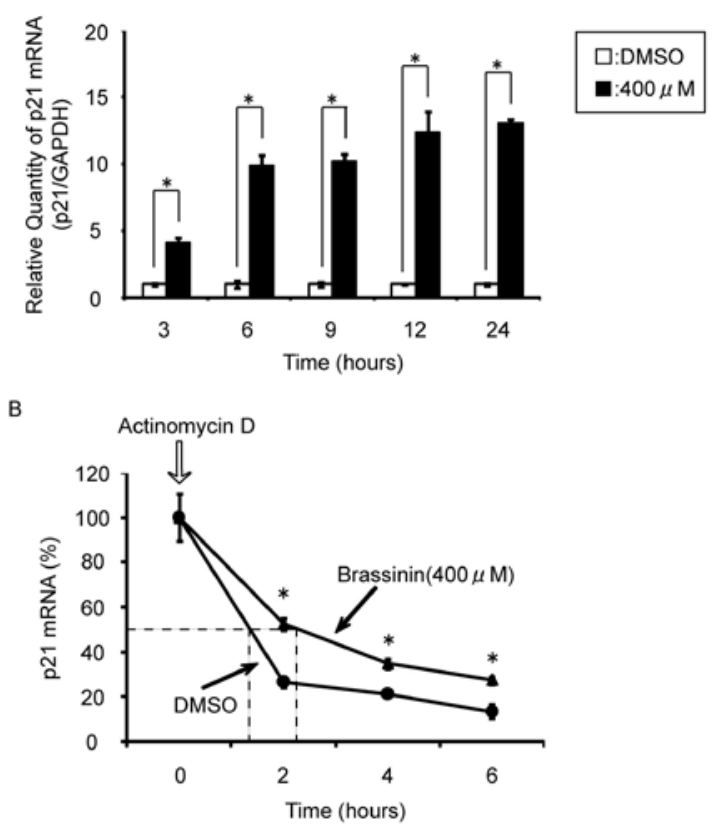

important pathways for carcinogenesis $(7,8)$. As previously reported, inhibition of this signaling pathway causes cell cycle arrest at the G1 phase accompanied by an increase of p27 $(9,12)$ and/or p21 (13). We then investigated whether the PI3K/Akt signaling pathway is a possible candidate for a target of brassinin. As shown in Fig. 5A, the expression of phosphorylated Akt was decreased remarkably by the treatment with brassinin for $24 \mathrm{~h}$, whereas no any obvious effect on the MEK/ERK pathway was observed. We therefore investigated the phos-

Figure 3. Brassinin induces p21 mRNA expression in HT-29 cells. (A) A realtime RT-PCR system was employed to measure the expression of p21 mRNA of the HT-29 cells treated with DMSO alone (open box) or $400 \mu \mathrm{mol} / 1$ brassinin (closed box). " $\mathrm{p}<0.01$, compared with the DMSO-treated control. (B) A realtime RT-PCR system was employed to measure the expression of p21 mRNA of the HT-29 cells treated with actinomycin D for the indicated times after the treatment with DMSO alone (circle) or $400 \mu \mathrm{mol} / 1$ brassinin (triangle) for $6 \mathrm{~h}$ " $\mathrm{p}<0.01$, compared with the DMSO-treated control. 

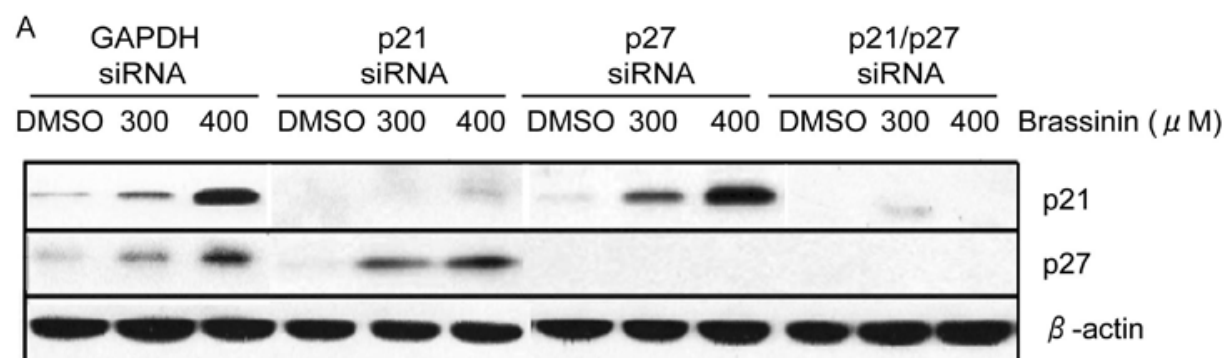

B

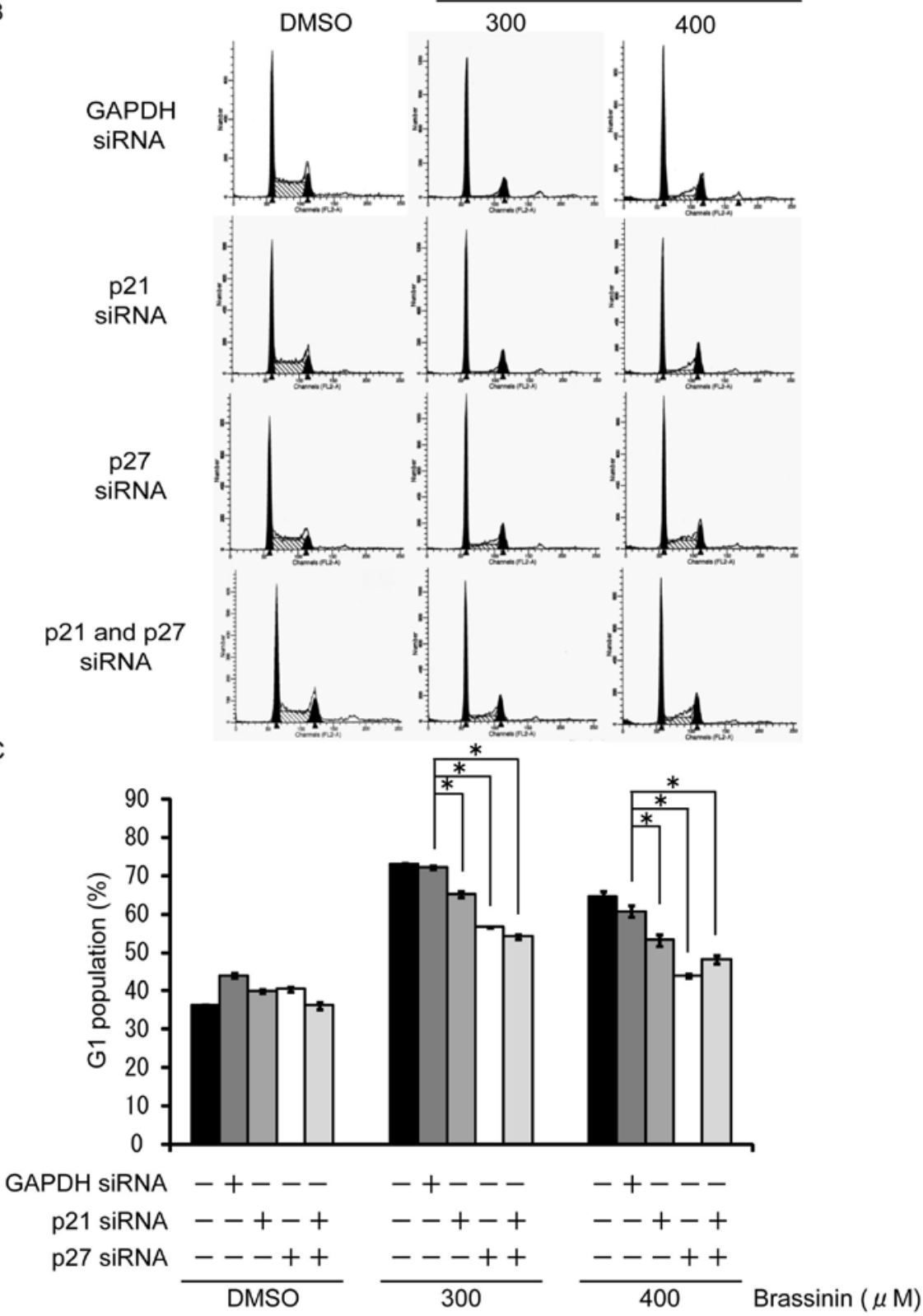

Figure 4. Antiproliferative effect of brassinin is dependent on p21 and/or p27. (A) The effect of knockdown of p21 and/or p27 on protein expressions by Western blotting. HT-29 cells were transiently transfected with siRNA as indicated for $24 \mathrm{~h}$ after incubation with DMSO alone, or 300 or $400 \mu \mathrm{mol} / 1 \mathrm{brassinin}$ for $24 \mathrm{~h}$. $\beta$-actin was used as a loading control. (B and C) The effect of knockdown of p21 and/or p27 on cell cycle arrest by the treatment with brassinin. HT-29 cells were transiently transfected with siRNAs as indicated for $24 \mathrm{~h}$ after the treatment with DMSO alone, or $300 \mathrm{or} 400 \mu \mathrm{mol} / \mathrm{l}$ brassinin for $24 \mathrm{~h}$. Representative patterns of histograms of the cell cycle analysis by flow cytometry (B). The analytical data of the percentage in G1 phase are shown in (C). The data represent means of triplicate experiments and are shown as means $\pm \mathrm{SD}$. ${ }^{*} \mathrm{p}<0.01$, compared with the DMSO-treated control.

phorylation state of typical elements of the PI3K/Akt pathway, such as PTEN, PDK1, and GSK-3 $\beta$. As shown in Fig. 5B, we found that phosphorylation of PDK1 was decreased by the treatment with brassinin for $24 \mathrm{~h}$, whereas phosphorylation of PTEN was not changed. Moreover, the phosphorylation of GSK- $3 \beta$ was also decreased. Furthermore, we investigated the 
A

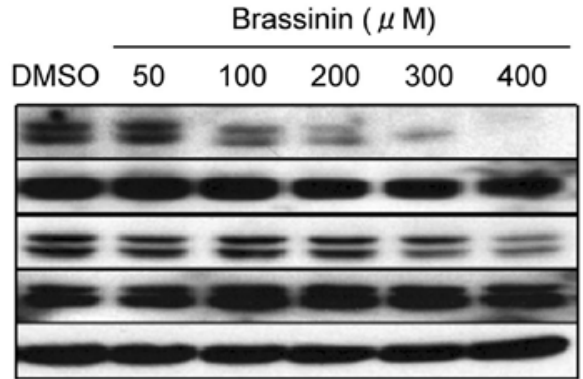

p-Akt(Ser 473)

total-Akt

p-ERK

total ERK

$\beta$-actin

B

\begin{tabular}{lccccc} 
& \multicolumn{5}{c}{ Brassinin $(\mu \mathrm{M})$} \\
\cline { 2 - 6 } DMSO & 50 & 100 & 200 & 300 & 400
\end{tabular}

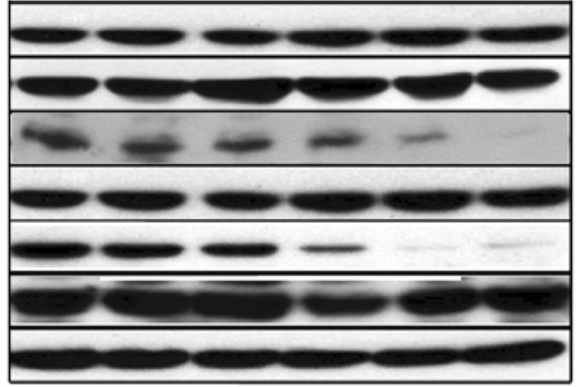

p-PTEN

total-PTEN

p-PDK1

total PDK1

p-GSK3 $\beta$

total GSK3 $\beta$

$\beta$-actin

C
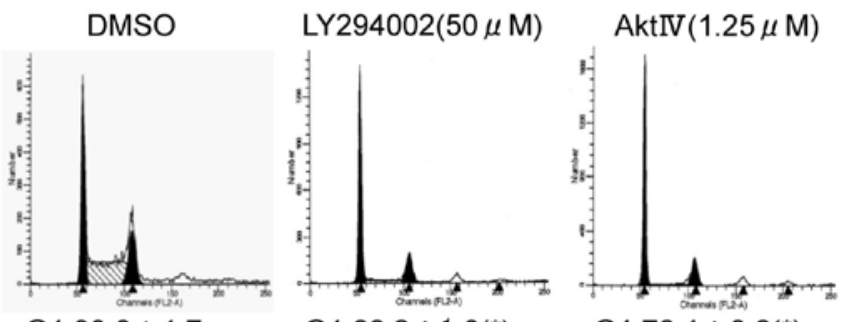

$\mathrm{G} 1: 33.0 \pm 1.7$

G1:68.2 $\pm 1.0\left(^{*}\right)$

$\mathrm{G} 1: 76.1 \pm 0.8\left(^{*}\right)$

S : $46.5 \pm 0.9$

$\mathrm{S}: 15.1 \pm 2.1$

$S: 5.0 \pm 0.6$

D

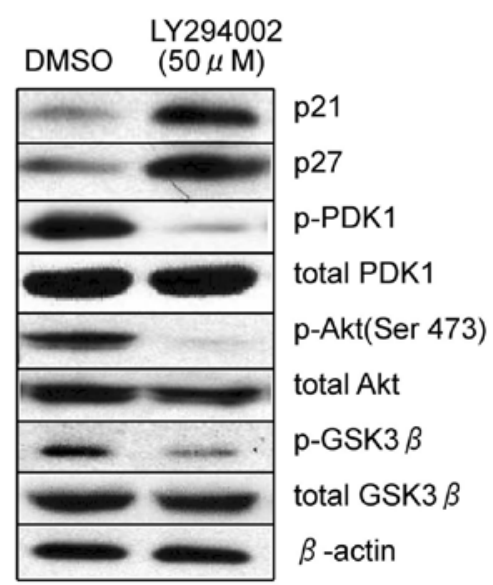

E

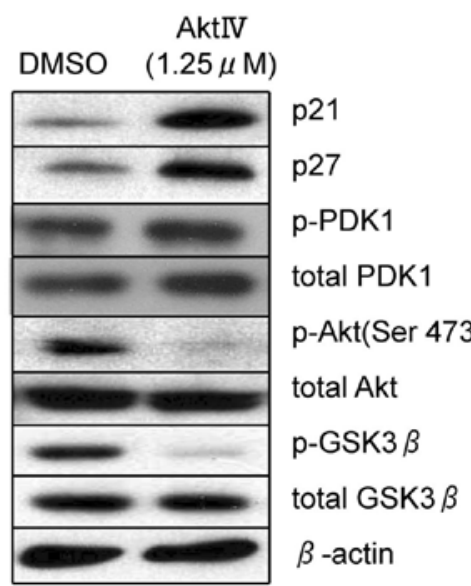

Figure 5. Brassinin inhibited PI3K-Akt signaling pathway. The effect of brassinin at the indicated concentrations for $24 \mathrm{~h}$ on phosphorylation status of Akt and ERK (A), or PTEN, PDK1, or GSK-3 $\beta$ (B), analyzed by Western blotting. $\beta$-actin was used as a loading control. (C) Representative histogram patterns of the cell cycle analysis of the HT-29 cells treated with control DMSO, PI3K inhibitor (LY294002), or Akt inhibitor (Akt IV) at the indicated concentrations for $24 \mathrm{~h}$. The data represent means of triplicate experiments and are shown as means $\pm \mathrm{SD}$. " $\mathrm{p}<0.01$, compared with the DMSO-treated control. (D and E) Western blots of the indicated proteins from the HT-29 cells treated with the indicated concentrations of LY294002 or Akt IV for $24 \mathrm{~h}$. $\beta$-actin was used as a loading control.

effect of the inhibition of the PI3K/Akt pathway on the cell cycle progression of HT-29 cells using PI3K and Akt inhibitors, such as LY294002 and Akt IV, respectively. As shown in Fig. 5C, FACS analysis revealed that 24-h exposure to LY294002 or Akt IV induced cell cycle arrest at the G1 phase.
At the same time, increases of p21 and p27 and decreases of phosphorylated Akt and GSK-3 $\beta$ were observed (Fig. 5D and E). These results suggest that the inactivation of the PI3K/ Akt pathway is involved in brassinin-induced cell cycle arrest at the G1 phase in HT-29 cells. 
A pcDNA wt Akt mt Akt Amt Akt

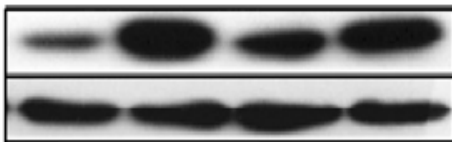

total Akt

$\beta$-actin

B

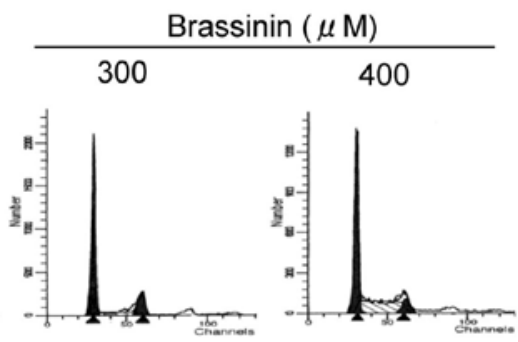

pcDNA

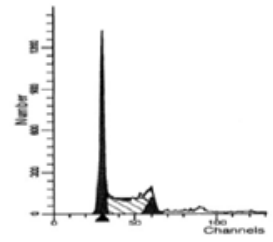

DMSO

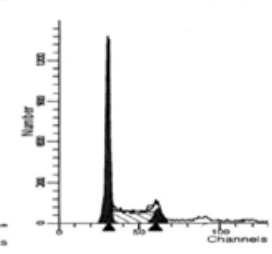

wild-type

Akt
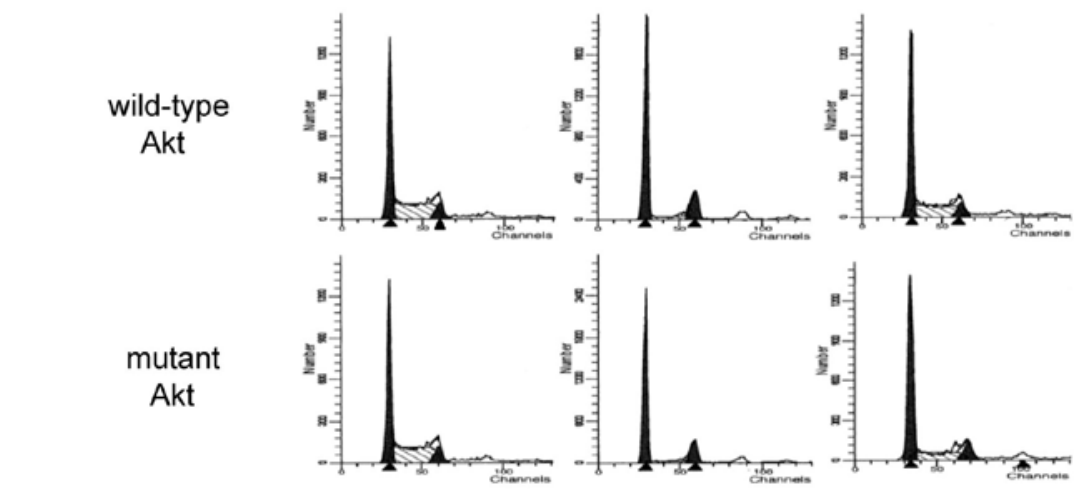

constitutively active
Akt
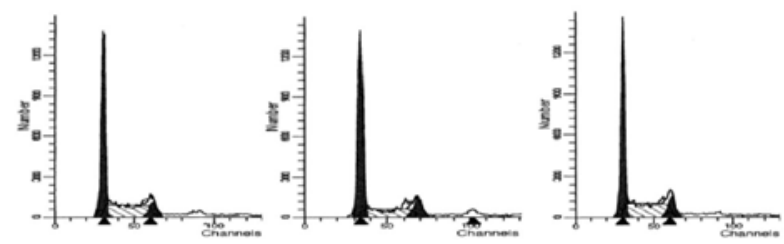

C

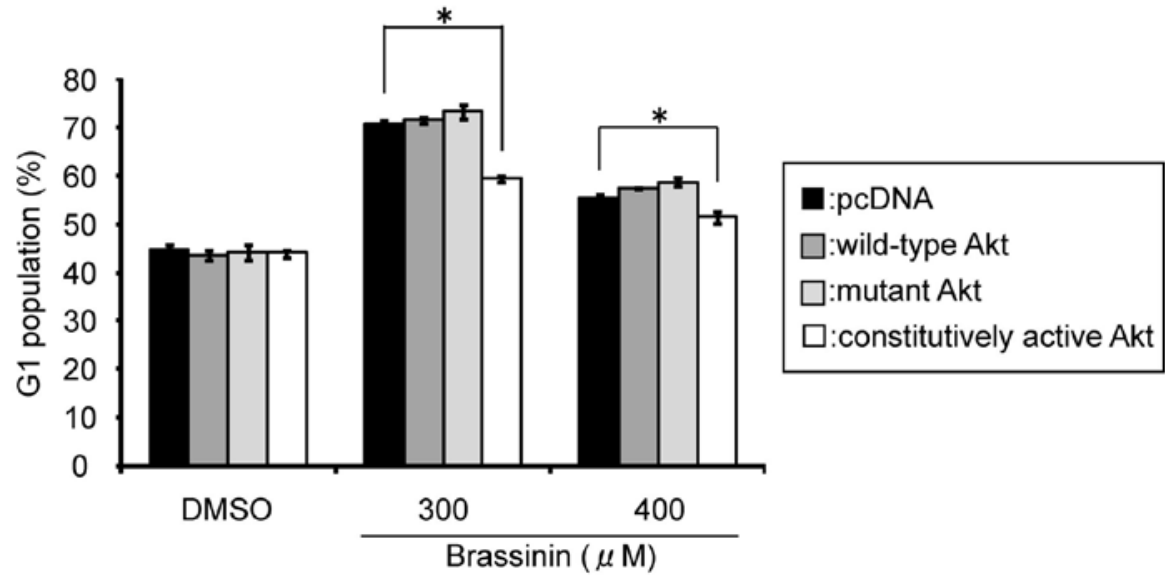

Figure 6. Overexpression of constitutively active Akt mutant partially weakens G1 arrest induced by brassinin. (A) Western blots of Akt in the HT-29 cells transiently transfected with Akt expression vectors (wild-type Akt, mutant Akt, constitutively active Akt) for $48 \mathrm{~h}$. $\beta$-actin was used as a loading control. (B) Representative histogram patterns of the cell cycle analysis of the HT-29 cells treated with DMSO alone, or 300 or $400 \mu \mathrm{mol} / 1$ brassinin for $24 \mathrm{~h}$ after transfection with Akt expression vectors (wild-type Akt, mutant Akt, constitutively active Akt) for $48 \mathrm{~h}$. The analytical data of the percentage of G1 phase populations are shown in (C). The data represent means of triplicate experiments and are shown as means $\pm v S D$. ${ }^{*} p<0.01$, compared with the vacant vector pcDNA as a control.

Constitutively activated Akt represses the cell cycle arrest at the Gl phase by brassinin. To further estimate the effect of brassinin on the PI3K-Akt pathway, we transiently transfected each Akt expression vector (wild-type Akt, negative mutant Akt, or constitutively active mutant Akt) into HT-29 cells treated with or without brassinin. As shown in Fig. 6A, the 
expression of each exogenous Akt protein was confirmed in HT-29 cells. As shown in Fig. 6B and C, transfection of constitutively active Akt repressed the cell cycle arrest at the G1 phase induced by treatment with 300 or $400 \mu \mathrm{mol} / 1$ brassinin slightly but significantly; however, transfection of control or wild-type Akt or inactivated Akt did not. These results suggest that G1 phase arrest induced by brassinin involves the inhibition of the PI3K-Akt pathway in HT-29 cells.

\section{Discussion}

Brassinin, a component of cruciferous vegetables, has been suggested as a potential cancer preventive or anti-tumor agent in animal models (3-5), but little is known about its inhibitory mechanism on the growth of cancer cells. We found that brassinin causes G1-phase arrest in human colon cancer HT-29 cells by inhibiting the PI3K-Akt signaling pathway accompanied by up-regulation of p21 and p27. We therefore examined the contribution of p21 and/or p27 to G1-phase arrest by brassinin by knockdown of these expressions (Fig. 4). Interestingly, it has also been reported that phytochemicals derived from cruciferous vegetables, such as I3C, sulforaphane, and DIM, induced expressions of $\mathrm{p} 21$ and/or p27 protein and cell cycle arrest at the G1 phase (14-16). In addition, I3C has been shown to inhibit the phosphorylation of Akt (17). Many reports have suggested that inhibition of PI3K-Akt signaling pathway leads to G1-phase arrest in various cancer cells $(9,12,13,17-20)$. In line with these findings, we found that brassinin inhibited phosphorylation of Akt and induced expressions of both p21 and p27 followed by cell cycle arrest at the G1 phase. Collectively, components of cruciferous vegetables may act cooperatively in similar mechanisms inhibiting the growth of cancer cells.

We investigated the molecular mechanism of p21 induction by brassinin, and found that brassinin induces p21 at the mRNA level by stabilizing mRNA (Fig. 3). These results suggest that post-transcriptional mechanisms may be involved in the induction of p21 by brassinin. On the other hand, we observed a decrease of phosphorylated Akt in the cells treated with brassinin (Fig. 5), and phosporylated Akt is known to inactivate p38 and/ or JNK signaling pathway (21-24). It has also been reported that activation of p38 and/or JNK signaling pathway stabilizes p21 protein and induces cell cycle arrest at the G1 phase (25). Therefore, we hypothesize that brassinin activates p38 and/or JNK signaling pathway via inactivation of Akt and stabilization of p21 protein. It is also known that p27 is phosphorylated by Akt and promptly degraded by proteasome (26). We observed an increase of p27 protein but not of mRNA by the treatment with brassinin (Fig. 2). These data are not contradictory to our hypothesis that $\mathrm{p} 21$ and p27 are stabilized by inactivation of Akt.

Our novel findings shed new light on the molecular mechanisms for inhibitory effects of brassinin on the growth of cancer cells, and raise a possibility of brassinin as a potential anticancer and/or cancer preventive agent. However, Banerjee et al have reported that the maximum concentration of brassinin is approximately $7 \mu \mathrm{mol} / 1$ and its half-life in the plasma concentration is very short (5). They have also developed a synthetic derivative, 5-bromo-brassinin, which is more stable in plasma than brassinin. In the future, the development of more stable derivatives may be important for application in vivo, and further study is required to improve the biological efficacy of brassinin.

\section{Acknowledgements}

We would like to thank Dr John D. Minna (Hamon Center for Therapeutic Oncology Research, University of Texas Southwestern Medical Center) and Dr Jim Woodgett (The Samuel Lunenfeld Research Institute, Mount Sinai Hospital) for kindly providing expression vectors for human wild-type Akt (pAkt), mutant Akt (pAktMUT), and constitutively active Akt (pAktDD). The study was partially supported by a Grantin-aid from the Japanese Ministry of Education, Culture, Sports, Science and Technology, and a Grant-in-aid for the Encouragement of Young Scientists from the Japan Society for the Promotion of Science.

\section{References}

1. Mezencev R,Mojzis J,Pilatova M and Kutschy P: Antiproliferative and cancer chemopreventive activity of phytoalexins: focus on indole phytoalexins from crucifers. Neoplasma 50: 239-245, 2003.

2. Bonnesen C, Eggleston IM and Hayes JD: Dietary indoles and isothiocyanates that are generated from cruciferous vegetables can both stimulate apoptosis and confer protection against DNA damage in human colon cell lines. Cancer Res 61: 6120-6130, 2001.

3. Mehta RG, Liu J, Constantinou A, Thomas CF, Hawthorne M, You M, Gerhuser C, Pezzuto JM, Moon RC and Moriarty RM: Cancer chemopreventive activity of brassinin, a phytoalexin from cabbage. Carcinogenesis 16: 399-404, 1995.

4. Gerhauser C, You M, Liu J, Moriarty RM, Hawthorne M, Mehta RG, Moon RC and Pezzuto JM: Cancer chemopreventive potential of sulforamate, a novel analogue of sulforaphane that induces phase 2 drug-metabolizing enzymes. Cancer Res 57: 272-278, 1997.

5. Banerjee T, Duhadaway JB, Gaspari P, Sutanto-Ward E, Munn DH, Mellor AL, Malachowski WP, Prendergast GC and Muller AJ: A key in vivo antitumor mechanism of action of natural productbased brassinin is inhibition of indoleamine 2,3-dioxygenase. Oncogene 27: 2581-2587, 2008.

6. Pilatova M, Sarissky M, Kutschy P, Mirossay A, Mezencev R, Curillova Z, Suchy M, Monde K, Mirossay L and Mojzis J: Cruciferous phytoalexins: antiproliferative effects in T-Jurkat leukemic cells. Leuk Res 29: 415-421, 2005.

7. Liang J and Slingerland JM: Multiple roles of the PI3K/PKB (Akt) pathway in cell cycle progression. Cell Cycle 2: 339-345, 2003.

8. Osaki M, Oshimura M and Ito H: PI3K-Akt pathway: its functions and alterations in human cancer. Apoptosis 9: 667-676, 2004

9. Chen XL, Ren KH, He HW and Shao RG: Involvement of PI3K/ AKT/GSK3 $\beta$ pathway in tetrandrine-induced G1 arrest and apoptosis. Cancer Biol Ther 7: 1073-1078, 2008.

10. Waldman T, Kinzler KW and Vogelstein B: p21 is necessary for the p53-mediated G1 arrest in human cancer cells. Cancer Res 55: 5187-5190, 1995.

11. Pan MH, Chen WJ, Lin-Shiau SY, Ho CT and Lin JK: Tangeretin induces cell-cycle G1 arrest through inhibiting cyclin-dependent kinases 2 and 4 activities as well as elevating Cdk inhibitors p21 and p27 in human colorectal carcinoma cells. Carcinogenesis 23: 1677-1684, 2002.

12. Casagrande F, Bacqueville D, Pillaire MJ, Malecaze F, Manenti S, Breton-Douillon M and Darbon JM: G1 phase arrest by the phosphatidylionsitol 3-kinase inhibitor LY294002 is correlated to up-regulation of p27 $7^{\mathrm{Kipl}}$ and inhibition of G1 CDKs in choroidal melanoma cells. FEBS Lett 422: 385-390, 1998.

13. Gao N, Zhang Z, Jiang BH and Shi X: Role of PI3K/AKT/mTOR signaling in the cell cycle progression of human prostate cancer. Biochem Biophys Res Commun 310: 1124-1132, 2003.

14. Chinni SR, Li Y, Upadhyay S, Koppolu PK and Sarkar FH: Indole-3-carbinol (I3C) induced cell growth inhibition, G1 cell cycle arrest and apoptosis in prostate cancer cells. Oncogene 20: 2927-2936, 2001.

15. Matsui TA, Murata H, Sakabe T, Sowa Y, Horie N, Nakanishi R, Sakai T and Kubo T: Sulforaphane induces cell cycle arrest and apoptosis in murine osteosarcoma cells in vitro and inhibits tumor growth in vivo. Oncol Rep 18: 1263-1268, 2007. 
16. Choi HJ, Lim do Y and Park JH: Induction of G1 and G2/M cell cycle arrests by the dietary compound 3,3-diindolylmethane in HT-29 human colon cancer cells. BMC Gastroenterol 9: 39, 2009.

17. Aggarwal $\mathrm{BB}$ and Ichikawa $\mathrm{H}$ : Molecular targets and anticancer potential of indole-3-carbinol and its derivatives. Cell Cycle 4: $1201-1215,2005$

18. Shukla S and Gupta S: Apigenin-induced cell cycle arrest is mediated by modulation of MAPK, PI3K-Akt, and loss of cyclin D1 associated retinoblastoma dephosphorylation in human prostate cancer cells. Cell Cycle 6: 1102-1114, 2007.

19. Gao N, Flynn DC, Zhang Z, Zhong XS, Walker V, Liu KJ, Shi X and Jiang BH: G1 cell cycle progression and the expression of G1 cyclins are regulated by $\mathrm{PI} 3 \mathrm{~K} / \mathrm{AKT} / \mathrm{mTOR} / \mathrm{p} 70 \mathrm{~S} 6 \mathrm{~K} 1$ signaling in human ovarian cancer cells. Am J Physiol Cell Physion 287: C281-C291, 2004

20. Weng LP, Smith WM Dahia PL, Ziebold U, Gil E, Lees JA and Eng C: PTEN suppresses breast cancer cell growth by phosphatase activity-dependent G1 arrest followed by cell death. Cancer Res 59: 5808-5814, 1999.

21. Widenmaier SB, Ao Z, Kim SJ, Warnock G and Mclntosh CH: Suppresion of p38 MAPK and JNK via Akt-mediated inhibition of apoptosis signal-regulating kinase 1 constitutes a core component of the $\beta$-cell pro-survival effects of glucose-dependent insulinotropic polypeptide. J Biol Chem 284: 30372-30382, 2009.
22. Pan J, Chang Q, Wang X, Son Y, Zhang Z, Chen G, Luo J, Bi Y, Chen F and Shi X: Reactive oxygen species-activated Akt/ASK1/ p38 signaling pathway in nickel compound-induced apoptosis in BEAS 2B cells. Chem Res Toxicol 23: 568-577, 2010.

23. Yoon SO, Kim MM, Park SJ, Kim D, Chung J and Chung AS: Selenite suppresses hydrogen peroxide-induced cell apoptosis through inhibition of ASK1/JNK and activation of PI3-K/Akt pathways. FASEB J 16: 111-113, 2002.

24. Ichijo H, Nishida E, Irie K, Ten Dijke P, Saitoh M, Moriguchi T, Takagi M, Mutsumoto K, Miyazono K and Gotoh Y: Induction of apoptosis by ASK1, a mammalian MAPKKK that activates SAPK/JNK and p38 signaling pathways. Science 275: 90-94, 1997.

25. Kim GY, Mercer SE, Ewton DZ, Yan Z, Jin K and Friedman E: The stress-activated protein kinases p38 and JNK stabilize p21 $1^{\mathrm{Cip}}$ by phosphorylation. J Biol Chem 277: 29792-29802, 2002.

26. Rassidakis GZ, Feretzaki M, Atwell C, Grammatikakis I, Lin Q, Lai R, Claret FX, Medeiros LJ and Amin HM: Inhibition of Akt increases p27 ${ }^{\mathrm{Kipl}}$ levels and induces cell cycle arrest in anaplastic large cell lymphoma. Blood 105: 827-829, 2005. 